\title{
Bioindication of PAHs and Palladium Pollution from Road Traffic
}

\author{
By Nathalie Clement* \\ Bogdan Muresan-Paslaru ${ }^{\dagger}$ \\ Denis Francois ${ }^{*}$
}

\begin{abstract}
Polycyclic aromatic hydrocarbons (PAHs) and palladium are associated with emissions from diesel and gasoline vehicles respectively. Only a few studies have focused on their effects on roadside ecosystems. Bio-monitoring can reveal the environmental health. This study aims at evaluating the contamination level of environmental compartments and identifying relevant organisms for the biomonitoring of PAHs and Pd. First, in order to assess each pollution extent a field and a forest were investigated near a heavy-traffic highway. Atmospheric PAHs were measured. PAHs and Pd contents were analyzed on soil and indigenous organisms. Second, based on these results and the literature, four plants were selected to be tested in a growth chamber with standard soil. Trifolium repens, Lotus corniculatus were exposed to PAHs; Festuca arundinacea, Lolium perenne to Pd. Parameters related to germination and aerial parts were regarded. The results show that Trifolium repens could be a potential bio-indicator of PAHs through the number of leaves, and Festuca arundinacea through its stretched length.
\end{abstract}

Keywords: Air, Bio-monitoring, Environmental health, Plants, Pollution, Soil

\section{Introduction}

It is broadly acknowledged that road traffic contributes to air pollution resulting in local and global scale ecological and health damages: among which are, global warming, water acidification, respiratory and immune system diseases. A wide variety of pollutants ranging from major and heavy metals to persistent organics have been studied in exhaust emissions, roadside particles, surface soils, sediments and/or aquatic systems (Giordano et al., 2010; Wang et al., 2015; Gonzalez and Rodriguez, 2013). However, there is currently lack of data about the effects of vehicular emissions on the roadside organisms. This study focuses on two distinct pollutants of contrasting vehicular origins: Polycyclic Aromatic Hydrocarbons (PAHs) and palladium (Pd). PAHs are carcinogenic organics that dominantly come from diesel emissions whereas $\mathrm{Pd}$ is an emerging pollutant historically used in the catalytic gasoline vehicle 'converters. On the one hand, high PAHs levels have been found in the first meters from the road carriageway (Viskari et al., 1997; Gateuille et al., 2014) but their post-depositional fate and potential transfers toward the local

\footnotetext{
* PhD Student, ADEME-IFSTTAR,France.

${ }^{\dagger}$ Researcher, IFSTTAR, France.

Researcher, IFSTTAR, France.
} 
organisms and more distant ecosystems is still poorly understood. On the other hand, a study by Zereini et al. (2007) corroborated by further researches (Helmers and Kümmerer, 2000; Gomez et al., 2002) demonstrated that the Pd loads in roadside soils markedly increased (punctually $>10$ times) over the past decades. This is all the more problematic since, among the platinum group elements, Pd seems to be the most bioavailable (Schäfer et al., 1998) and is released in the shape of nanoparticles (Zereini and Alt, 2006).

Despite the impregnation of environmental compartments with $\mathrm{Pd}$ and PAHs is now ascertained; only a few studies have focused on their effects on roadside exposed organisms. Besides, the necessary appraisal and evaluation of these effects may also serve to propose suitable tools for impact monitoring. If properly constructed and characterized, such tools may be useful for gauging the importance and the extent of contamination, the transformations undergone by PAHs and Pd and ensuing bioavailability changes as well as the eventual impregnation of the local trophic chains. Growing roadside organisms on contaminated soils represents a first step for estimating the biological effects of PAHs and Pd contaminations (Fletcher, 1991; Vernay et al., 2009). Hence, this study adopted a two-stage approach. Firstly, the fate of PAHs and Pd was studied in various roadside environmental compartments ranging from the atmosphere, to the surface soils and local organisms. This served to assess the contamination levels, the spatial extent of environmental contamination and the potential organism to be used in toxicity tests. Secondly, based on the in-situ measurements and existing bibliography, roadside organisms that meet specified PAHs or Pd sensitivity criteria were selected then tested for their response to increasing soil contamination levels. These tests aim at gaining clear information about the morphological and physiological functional traits that allow quantifying the organisms' $\mathrm{PAH}$ and $\mathrm{Pd}$ exposure.

\section{Materials and Methods for Diagnostic Study}

\section{Study Sites and Selection Criteria}

In order to identify the study sites fitted to the appraisal of both the PAHs and the Pd environmental fate, six criteria presenting a major importance in pollutants dispersion have been analyzed. These consisted of: i) the traffic intensity, ii) the uniformity and iii) uniqueness of the vehicular source among sampling sites, iv) the existence of established databases for climate and meteorological conditions, v) the nature of the ground, vi) the presence of the sampling of contrasting vegetation covers. Local traffic intensity has been evaluated in order to determine a daily vehicle flow representative of the French mean for highways. Sampling sites ought to be rural in order to limit the influence of industrial and residential sources. The local climate and meteorological conditions have been considered for the site to be localized downstream the vehicular PAH and Pd emissions. Moreover, soil substrata having high sand contents had to be avoided. Finally, in order to test the effect 
of vegetation cover on pollutant dispersion, the sampling sites involved an open field as well as a mature forest under consistent traffic and environmental conditions. Besides, the local topography of the ground should be flat not affected by the presence of cuts and fills.

Responding to all those criteria, two sites, arable field called (site A) and a forest (site B) have been retained near the A71 highway in Sologne $200 \mathrm{~km}$ south of Paris (France). A $20 \mathrm{~m}$-wide right-of-way (ROW) was located near each side of the carriageway. The ROW differs notably from the crossed milieus and thus has been considered a distinct type of environment. Two ROWs have been defined herein, i.e. ROW A and ROW B, located beside each of the study sites (A and B, respectively).

\section{Sampling}

Three transects ( $200 \mathrm{~m}$ in length) were perpendicularly positioned from the carriageway of the A 71 highway. These were separated one from another by a distance of $33 \mathrm{~m}$. Five sampling points were placed along each transect so as to capture the traffic-induced contamination gradient: at 2, 5, 20, 50 and 200 meters, respectively.

Both the surface soils and local organisms were collected at each sampling point. The surface soils were collected down to $20 \mathrm{~cm}$ deep. The ROW A, ROW B and the site A overlaying organisms were essentially composed by herbaceous plants. Thus, the plant communities were collected indiscriminately within a $0.25 \mathrm{~m}^{2}$ square. Festuca arundinacea $(95 \%)$ was the dominant species of the ground cover in ROW A and ROW B. Different species, among which were, Matricaria perforata, Myosotis arvensis, Plantago major, Senecio sp, Stellaria sp, Taraxacum officinale and Trifolium repens, composed the field plant community.

At site $B$, three representative vegetation species were collected at different heights: a moss (Scleropodium purum Hedw) at soil level; bramble leaves (Rubus sp) at a $1 \mathrm{~m}$ height; and ivy leaves (Hedera helix L.) at a $2 \mathrm{~m}$ height. Each species was collected individually and the collected mass was close to $100 \mathrm{~g}$ (fresh weight).

Along with the plant communities and vegetation samples, earthworm communities were also collected. This was done by collecting indistinctly all the individuals from $2 \mathrm{~m}$ long by $0.5 \mathrm{~m}$ wide and $0.20 \mathrm{~m}$ deep surface soils monoliths. Earthworms were found at ROW A and ROW B sampling sites as well as at site A. The high moisture contents of site B soils limited the importance of their population. Where available, up to $\sim 40 \mathrm{~g}$ of earthworms were collected.

\section{Analytical Section}

In order to analyse only the Pd absorbed by organisms, plants and earthworms samples were rinsed with distilled water before extraction. Regarding the soil, all samples were directly digested with aqua regia. Plants 
and earthworms were digested using only nitric acid. After keeping the samples at room temperature, extract solutions were filtered prior to analysis. Palladium concentrations were determined by means of a fully calibrated quadrupole Inductively Coupled Plasma-Mass Spectrometry (Bruker ICP-MS 820 equipment) according to ISO 17294-1 and ISO 17294-2. The limit of detection (LoD) was close to $35 \mathrm{ng} . \mathrm{L}^{-1}$, which represents $\sim 1.7 \mathrm{ng} . \mathrm{g}^{-1}$. The limit of quantification (LoQ) was $90 \mathrm{ng}$ in the digestion mixtures, which represents $\sim 5.0 \mathrm{ng} . \mathrm{g}^{-1}$. In order to improve measurement correctness, helium plasma was used for the removal of multiple polyatomic interferences.

The atmospheric fallout was estimated by using a dust monitor (EDM 1.108) linked to a particulate PAH sensor (Model 130). Then, the particle size distribution between $0.25 \mu \mathrm{m}$ and $22.5 \mu \mathrm{m}$ and a local concentration of the sum of all particle-bound PAHs was measured. The 16 priority PAHs from the United States Environmental Protection Agency (US-EPA, 2008) list were analyzed.

Grimm filters, soils and organism samples were extracted in a mixture of DCM and methanol using focused microwave-assisted extractions in close cells (Multiwave ${ }^{\mathrm{TM}} 3000$ from Anton Paar). Following the extractions, PAHsbearing solvents were concentrated by using a Rotavapor and brought with nheptane. The cleaned-up step was achieved through silica gel columns. The 16 PAHs designated by the US-EPA were analyzed by GC/MS (Focus DSQ single quadrupole from Thermo). Naphthalene, acenaphthylene and acenaphthene were excluded from data analyses because of their high standard vapor pressure. The remaining thirteen congeners are summed and named $\Sigma_{13} \mathrm{PAH}$. The mean recovery and variance associated with the accuracy for PAHs determinations were $107 \pm 8 \%$. Procedural blanks ranged from $0.5 \mathrm{ng}$ to $2 \mathrm{ng}$ and the detection limits were between $20 \mathrm{pg}$ and $50 \mathrm{pg}$.

\section{Materials and Methods for Phytotoxicity Tests}

\section{Selected Species}

The species selection was based on the diagnostic study results as well as the literature data relating to organism sensitivity with respect to the targeted pollutants. Sought organisms were expected to have a limited sensitivity with respect to other pollutants and background contaminants. Another important consideration for selection was the seed mixture usually sown in the ROW areas at a national level.

\section{$\underline{\text { Selected Species for Pd Phytotoxicity Tests }}$}

Regarding the dominant species of the ROW, few phytotoxicity studies have revealed some characteristics which lead to test Festuca arundinacea sensibility to Pd exposure. Besides, it is a model plant used in the ISO 22030 standard (2005), a chronic toxicity test on higher plants via soil quality. It 
maximizes phytoavailability of trace elements ( $\mathrm{As}, \mathrm{Cd}, \mathrm{Cu}, \mathrm{Pb}, \mathrm{Zn}$ ) in soils with different pollution sources and their physicochemical properties. Its rhizosphere microbial activity is able to degrade PAHs (Alam Cheema et al., 2009; Huang et al., 2004; Chi hua et al., 2006) and it seems to be resistant to PAHs exposure: an interesting property for a bioindicator candidate in order to avoid PAH interaction on palladium effects on the site.

Lolium perenne is the second dominant species of the standard national seed mixtures sown in highway ROW. It is a standardized biomonitoring species for phytotoxicity tests and its sensitivity to Pd has been underlined a long time ago (Benedict, 1970; Brenchley, 1934). Lolium perenne occurs naturally on heavy metal polluted sites (Arienzo et al., 2004). This means that it is able to support relatively high contamination levels, hence worth to be tested as a Pd bioindicator candidate.

\section{$\underline{\text { Selected Species for PAH Phytotoxicity Tests }}$}

Trifolium repens and Lotus corniculatus are not dominant in the standard seed mixture but these two species are commonly observed in national ROW and they have a wide natural distribution area. Scarce studies about PAHs effect on Trifolium repens growth are available: in Smith et al. $(2006 ; 2011)$ effects are observed from a $1000 \mathrm{mg} \cdot \mathrm{kg}^{-1} \mathrm{PAH}$ content and no effect on germination is underlined. Henner et al. (1999) shows that plant growth is reduced by an average contamination, and totally inhibited with heavy contamination. Regarding high PAH contamination, an effect on Lotus corniculatus growth is also observed but no effect is noted on germination (Smith et al., 2006; 2011).

\section{Test Protocol}

Exposure tests were conducted in a growth chamber according to the OCDE (2006) guidelines and the specific needs for each species (AFNOR, 2005). The growth parameters were: temperature: $19^{\circ} \mathrm{C}$, photoperiod: $16 \mathrm{~h}$, relative humidity: $70 \%$, light output: 300 to $400 \mathrm{mmol}$ photon $/ \mathrm{m}^{2} / \mathrm{s}$. To minimize the influential toxicological parameters, tests were conducted with standard soil (2.3 standard soil from LUFA Speyer) that shows close properties to the in-situ soil (sandy / clay). Palladium metallic powder (of $0.2-0.5 \mathrm{~nm}$ grain size) or a mixture of the US EPA's 16 priority PAHs were used to contaminate the soil. Prior to adding to the plants, contaminated soils were kept in glass jars surrounded by aluminum to allow equilibration. During 2 weeks, these were daily agitated for $5 \mathrm{~min}$. The final contents ranged from $10^{-6} \mathrm{mg} \cdot \mathrm{g}^{-1}$ $\Sigma_{13} \mathrm{PAH}$ to $10^{-1} \mathrm{mg} \cdot \mathrm{g}^{-1} \Sigma_{13} \mathrm{PAH}$ and from $10^{-3} \mathrm{mg} \cdot \mathrm{g}^{-1} \mathrm{Pd}$ to $10 \mathrm{mg} \cdot \mathrm{g}^{-1} \mathrm{Pd}$. These intervals correspond to a range varying exponentially from the natural level to an extreme pollution level. A positive Control with $\mathrm{Zn}$ was used to probe the sensitivity of the plant and the effectiveness of the experimental setup. A negative Control with acetonitrile, i.e. PAHs solvent, was equally performed. Uncontaminated soils were further used as a reference to gauge the effects of 
PAHs or Pd. Seeds are genetically stable varieties from RAGT Company. Initially, 27 seeds were sowed per pot, from which only 5 individuals were cultivated until the end of the tests.

\section{Studied Traits and Data Treatment Methods}

Toxicity tests aim at identifying at what level of soil contamination the effects on organisms become significant. This can be done by measuring morphological and physiological traits that reflect the sensibility of each plant to PAH and Pd exposure. These traits have been selected because of their direct impact in the physiological functioning of the organism and the link that can be done with the functioning of the community (Cornelissen et al., 2003; Gross, 2007).

\section{$\underline{\text { Germination }}$}

The percentage effect (PE) on the germination capacity was estimated relative to the initial number of grain sown and regarding the uncontaminated Controls. This was formulated as follows:

$$
\mathrm{PE}(\%)=\frac{\mathrm{SG}_{\mathrm{PAH} ; \mathrm{Pd}}-\mathrm{SG}_{0}}{\mathrm{SG}_{0}} \times 100
$$

where SG is the number of sprouted seeds per pot in the presence (PAHs; Pd in subscript) and absence ( 0 in subscript) of added pollutants. A germination time was also assessed and defined as the number of days needed in order to reach a given percentage of sprouted seeds per pot (AFNOR, 2005).

\section{$\underline{\text { Functional Traits }}$}

Plants are collected at different stages of growth. Besides, thinning which occurred on day 10, 20 and 30 following germination. Stem and root lengths; fresh, dry and calcined weight for vegetative and roots system were measured on each plant at these dates and at the end of the test: day 60 (D60). These were used to calculate water and mineral contents in the aerial and root parts. The number of leaves per plant was determined every 3 days. The stretched length corresponds on herbaceous, to a stem on which the youngest expanded leaf is selected (evergreen) and stretched to its maximum length along the stem axis (Cornelissen et al., 2003). This trait was also regularly measured on the five remaining individuals kept to evaluate the pollutant effect on plant growth.

At the end of the tests, several additional leave' traits have been measured: The Specific Leaf Area SLA corresponds to the ratio of the leaf area and its dry weight $\left(\mathrm{mm}^{2} \cdot \mathrm{mg}^{-1}\right)$, Leaf Dry Matter Content LDMC which was obtained by dividing leaf dry weight $(\mathrm{mg})$ by its fresh weight $(\mathrm{g})$ and Total Leaf Area TLA which is the sum of all healthy leaves surface fully developed and rigid without petiole $\left(\mathrm{mm}^{2}\right)$. Statistical analyzes were carried out on the vegetative part and on the roots over exposure time. Exhaustive analyzes were conducted for D60 
results. A global average-to-average comparison analysis was carried out between the trait results with respect to exposure conditions in order to assess the existence of significant differences. The average values were compared by pairs with the Tukey method.

\section{Results and Discussion}

Diagnostic Study

\section{$\underline{\text { Assessment of Pd Uptake through Transfer Coefficients }}$}

Transfer coefficient (TC) values were calculated as the ratio of the pollutant content of terrestrial organism (i.e. plants and earthworms) to the content in the soil (Ek et al., 2004). Figure 1 presents, sites A and B average TCs \pm standard deviation (in $\mathrm{ng}^{-1} \mathrm{~g}^{-1}$, dry weight) values for earthworms (EW), plant communities (PC), bramble leaves (BL) and ivy leaves (IL). Moss TC was not determined due to its root system absence.

Figure 1. Transfer Coefficients in Site A (Grey Symbols) and B (Black Symbols) for Earthworms (EW), Plant Communities (PC) In and Out of the Right of Way (ROW), for Bramble Leaves (BL) and Ivy Leaves (IL)

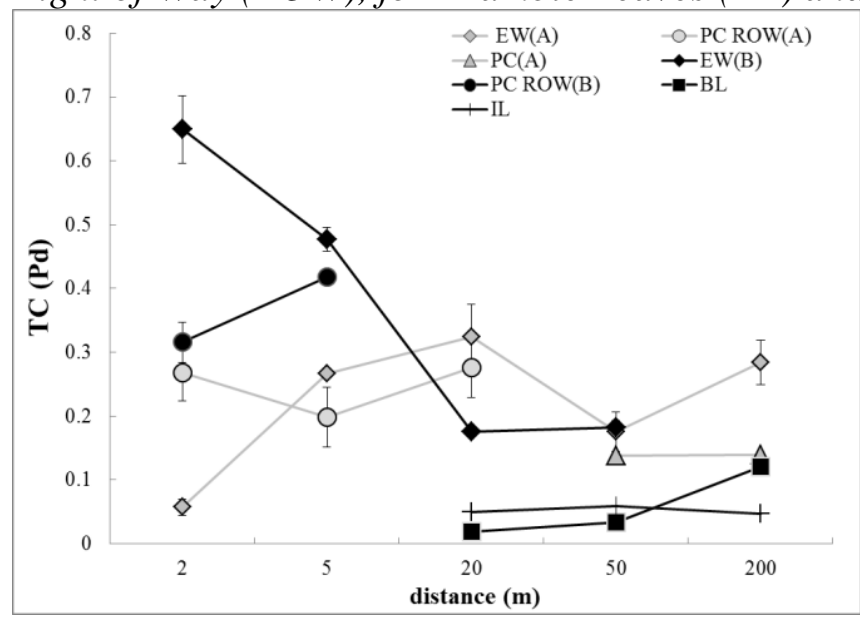

The gained results show that the organisms (especially the site B earthworms) are more contaminated with Pd toward the carriageway. This suggests that most of the direct effects of Pd emissions would be found in the first $20 \mathrm{~m}$ from the carriageway, which roughly corresponds to the ROW area. For instance, the highest TCs are observed for earthworms in site B at $2 \mathrm{~m}(0.65$ ng. $\left.\mathrm{g}^{-1}\right)$ and $5 \mathrm{~m}\left(0.48 \mathrm{ng} \cdot \mathrm{g}^{-1}\right)$. Like for earthworms, the highest TCs for plant communities are observed at site $B$ and reaches 0.42 at $5 \mathrm{~m}$. Interestingly, while the site B TCs are low outside the ROW, the site A organisms exhibit more homogeneous values between sampling locations. This indicates that changes in the vegetation cover and the local dynamics of these pollutants may notably influence the contamination of road organisms between the sampling 
sites. It is also worth noting that TC values are all below 1 . This means that no substantial bioaccumulation is observed in the tested organisms, which further suggests that, upon deposition, $\mathrm{Pd}$ contamination primarily remains in roadside soils. This preliminary result must be supported by further analyzes concerning the potential Pd transfer rates into the exposed organisms.

\section{Assessment of Pd Footprint through Accumulation Indexes}

With the local variation in the surface soil Pd contents, and when exclusively focusing on the TC values, any higher content organism may be considered as less contaminated than another, providing the soil within which it develops is more contaminated than the other. In order to avoid a misinterpretation caused by variation of contamination along transects and to assess a local contamination of a target organism, an indicator can be more relevant when it compares each specimen's content to a unique reference value (Jullien and François, 2006). This reference can be the background contamination of the soil (Soil Reference Value-SRV); or the organism pollutant content at the point where the background contamination of the soil is met (Earthworm reference value-EWRV; or Plant Community Reference Value-PCRV). The ratio between the organism's pollutant content and this background reference value determines an accumulation index (AI) (Figure 2).

Figure 2. Accumulations Indexes Calculated in Site A (Grey Symbols) and B (Black Symbols)

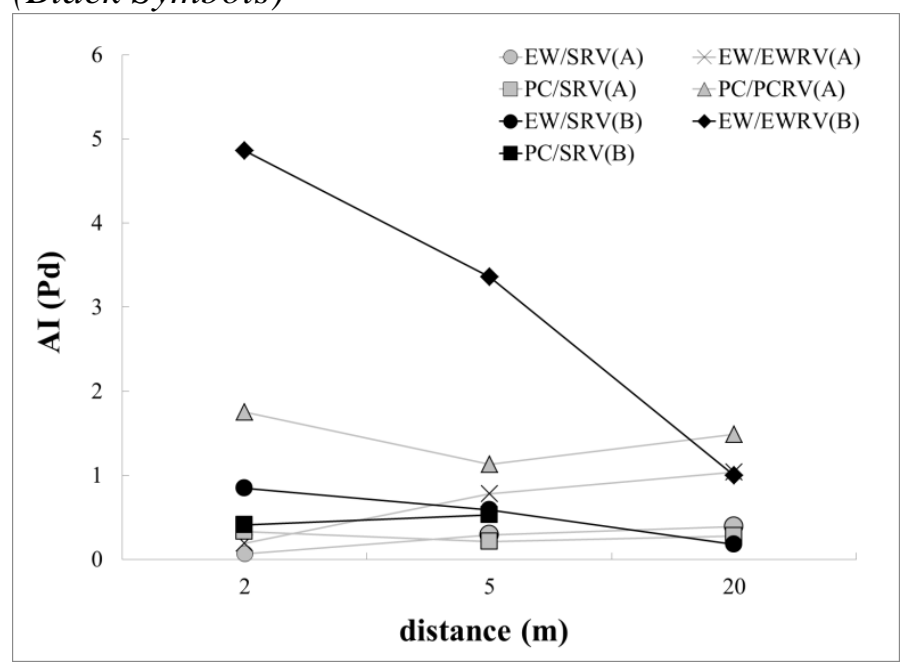

Regarding site A, the soil reference value for the Pd content is met at 200 $\mathrm{m}: \operatorname{SRV}(\mathrm{A})=47.49 \mathrm{ng} \cdot \mathrm{g}^{-1}$. For site $\mathrm{B}$, the SRV is met since $20 \mathrm{~m}: \mathrm{SRV}(\mathrm{B})=$ $44.79 \mathrm{ng} \cdot \mathrm{g}^{-1}$. The contamination of organisms at these respective points, in site $\mathrm{A}$, are $\mathrm{EW}_{200 \mathrm{~m}}(\mathrm{~A})=17.86 \mathrm{ng} \cdot \mathrm{g}^{-1}(\mathrm{EWRV}(\mathrm{A}))$ and $\mathrm{PC}_{200 \mathrm{~m}}(\mathrm{~A})=8.88 \mathrm{ng} \cdot \mathrm{g}-1$ $(\mathrm{PCRV}(\mathrm{A}))$. For site $\mathrm{B}, \mathrm{EW}_{20 \mathrm{~m}}(\mathrm{~B})=7.87 \mathrm{ng}^{-\mathrm{g}^{-1}}$.

The analysis of AI, based on the respective EWRV and PCRV shows some significant uptake within the ROW areas. Earthworms in ROW B present high AI between 2 and $20 \mathrm{~m}$ : the contents are almost 5 times the EWRV at $2 \mathrm{~m}$, and 
more than 3 times at 5 meters. In ROW A, no substantial accumulation effect has been evidenced due to a bias in sampling (discrimination of smaller, younger and less contaminated earthworms due to the presence of a geotextile close to the road). Nevertheless in site A, the plant community indicates a Pd accumulation with AI from 1.75 to1.13. Overall, TC and AI results lead to suppose that some in-situ plant species of the ROW areas could possibly be tested as potential passive bio-indicators to estimate palladium contamination in the roadside environment.

\section{Assessment of PAH Uptake through Transfer Coefficients}

PAH contents in organisms usually increase with the proximity to the carriageway. In site B, high contents in both surface soils and organisms were punctually observed $20 \mathrm{~m}$ from the carriageway (interface ROW- forest). This is followed by a pronounced decrease indicating the existence of a barrier effect that hinders the lateral dispersion of PAHs and presumably increases their local deposition onto the soils and local organisms. The highest TC values have been observed in ROW B earthworms and plant communities (Figure 3). This corresponds to the areas where the PAHs are emitted and tend to accumulate in the local atmosphere. The lowest TCs have been observed outside the ROW for plant communities, bramble and ivy leaves. The latter, however, shows higher values in a remote area $50 \mathrm{~m}$ from the carriageway. An important result is TC $>1$ in most points. This shows that PAHs accumulate in the roadside environmental compartments. It also points out the existence of pronounced variations in the accumulation pattern both in terms of the exposed organism and spatial exposure.

Figure 3. Transfer Coefficients in Sites A (Grey Symbols) and B (Black Symbols) for Earthworms (EW), Plant Communities (PC) In and Out of the Right of Way (ROW), for Bramble Leaves (BL) and Ivy Leaves (IL)

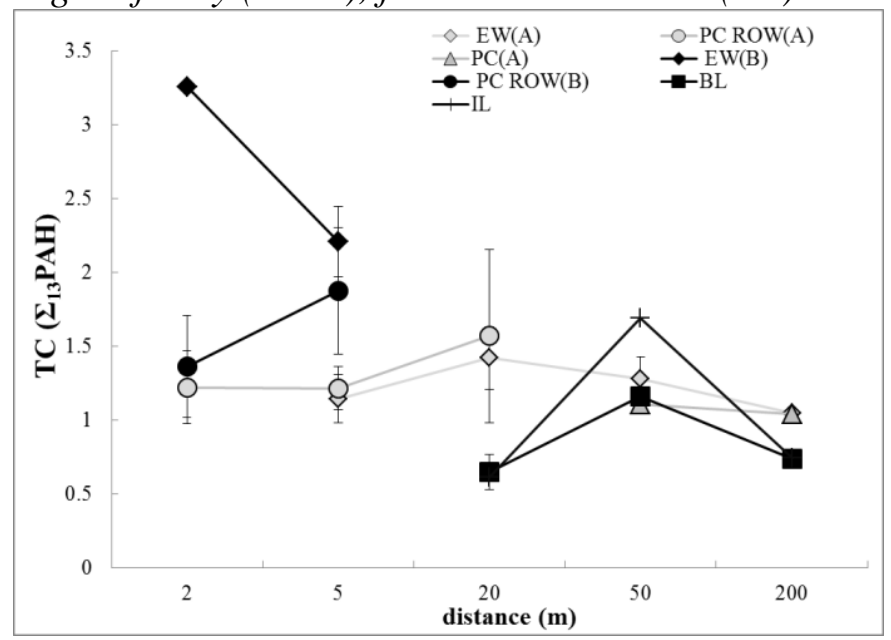

Taking the analyzed PAHs individually, it appeared that PAHs having 2-3 benzene rings concentrate widely in plant communities whereas PAHs with $\geq 4$ 
benzene rings usually accumulate in earthworm populations adjoining the highway. Plants' impregnation with lower PAHs could be partly explained by direct atmospheric contamination.

\section{Assessment of PAH Footprint through Accumulation Indexes}

The background soil content in $\Sigma_{13} \mathrm{PAH}$ in site $\mathrm{A}$ is measured at $50 \mathrm{~m}$ : $\operatorname{SRV}(\mathrm{A})=59.23 \mathrm{ng} \cdot \mathrm{g}^{-1}$. For site $\mathrm{B}, \mathrm{SRV}$ is met since $5 \mathrm{~m}: \mathrm{SRV}(\mathrm{B})=45.32$ ng. $\mathrm{g}^{-1}$. The contamination of the organisms at these respective points, in site $A$, are $\mathrm{EW}_{50 \mathrm{~m}}(\mathrm{~A})=58.32 \mathrm{ng} \cdot \mathrm{g}^{-1}(\operatorname{EWRV}(\mathrm{A}))$ and $\mathrm{PC}_{50 \mathrm{~m}}(\mathrm{~A})=67.69 \mathrm{ng} \cdot \mathrm{g}^{-1}$ $(\mathrm{PCRV}(\mathrm{A}))$. For site B, EW $\mathrm{EW}_{\mathrm{m}}(\mathrm{B})=89.57 \mathrm{ng} \cdot \mathrm{g}^{-1}$.

Most AI in ROWs are higher than 1 (Figure 4). This confirms the impregnation of the roadside organisms with PAHs. However, unlike for Pd, this suggests a contamination of the surface soils in conjunction with a significant uptake by the ROW organisms. In this regard, earthworms in ROW $\mathrm{B}$ present the highest AI, between 2 and $5 \mathrm{~m}$ (5.6-2). High AI values are also observed in many plant communities' samples collected both in ROWs A and $\mathrm{B}$ between 2 and $5 \mathrm{~m}$ (2.3-1.5 and 2.0-2.6, respectively).

It is worth to note that half-life of PAH depends on PAH congener (70 days for naphthalene, 230 days for fluorene) (Jones and Voogt, 1999; MacKay and Shin, 1991). In addition, this degradation time depends on various physical-chemical and biological factors e.g. photodegradation, oxidation, microbial activity. In average, the $\Sigma_{13} \mathrm{HAP}$ stocks in collected soils and organisms represent between $\sim 1 \%$ and $\sim 0.1 \%$ of cumulated emissions since the highway is opened (Clement et al., 2015). This means that PAHs do not accumulate in these compartments during exposure time. PAH are probably degraded and / or exported. So, PAHs recently deposited are measured in the organisms. Moreover, PAH levels increases are observed through plant communities and earthworms CT and AI collected in ROW B near the forest edge. These results indicate that most PAHs uptake might occur in the first 20 meters from the carriageway especially in closed environments where trees form a barrier that may intercept the vehicular PAHs.

Accordingly, the ROW organisms, such as herbs constitutive of the plant communities that display high TC and AI values can be regarded as potential organisms for $\mathrm{PAH}$ passive bio-monitoring. 
Figure 4. Accumulations Indexes Calculated in Site A (Grey Symbols) and B (Black Symbols)

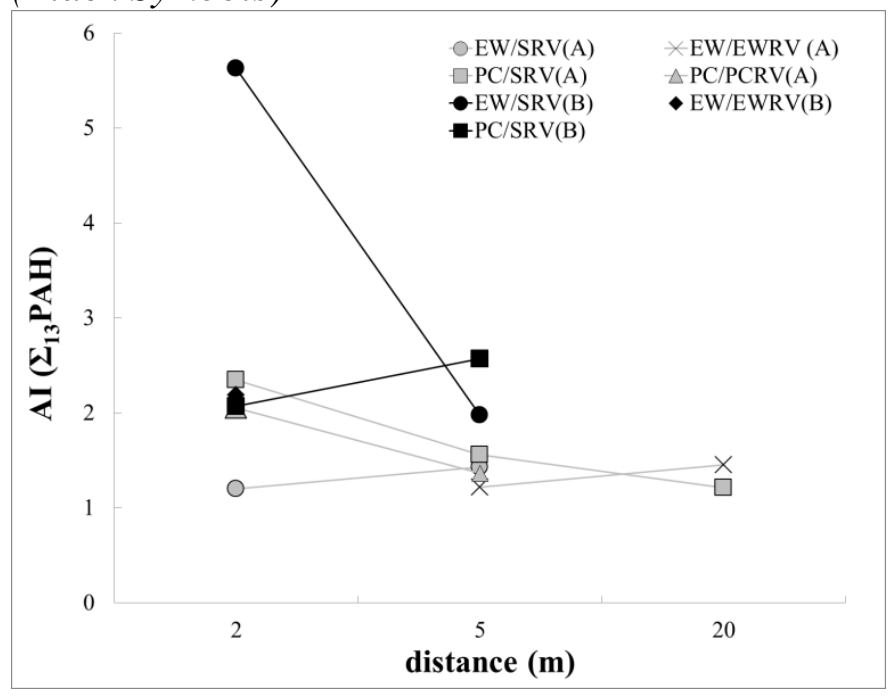

Results of Phytotoxicity Tests

Based on in-situ observations and the previously evoked selection criteria, four species were identified. Festuca arundinacea and Lolium perenne have been exposed to a range of $\mathrm{Pd}$ contents and Trifolium repens and Lotus corniculatus have been exposed to $\Sigma_{13} \mathrm{PAH}$ contents via standardized soil contamination. The effects on germination capacity and on germination rate have been analyzed.

Functional trait responses were measured to evaluate the various pollutant content effects and plant sensibility.

\section{$\underline{\text { Palladium Phytotoxicity Tests }}$}

\section{Germination Tests}

Seeds' germination is not significantly affected for both Festuca arundinacea and Lolium perenne. The germination capacity was more pronounced in contaminated soils than the Control. This effect was observed over the entire $\mathrm{Pd}$ content range and thus could constitute a $\mathrm{Pd}$ presence/absence indicator. The germination time for attaining $45 \%$ of Festuca arundinacea seed germination at $10 \mathrm{mg} \cdot \mathrm{g}^{-1} \mathrm{Pd}$ was significantly shorter that in the uncontaminated soil ( 4 vs. 22 days).

\section{Functional Traits Responses}

Changes in functional traits for Festuca arundinacea and Lolium perenne are presented in Figure 5. The symbols indicate for which trait a significant difference $(p<0.05)$ is observed between plants exposed to the different $\mathrm{Pd}$ contents, including the Control $\left(0 \mathrm{mg} \cdot \mathrm{g}^{-1}\right)$. Each symbol ( $\Theta$ : Stretched length; 
Ş: Specific leaf area; 6: Organic content / fresh matter; $U$ : Water content) corresponds to a specific trait.

Figure 5. Changes in Functional Traits for Festuca arundinacea (Right-hand Side) and Lolium perenne (Left-hand Side): Average-to-average Comparisons (ns: No Significant Difference)

\begin{tabular}{|c|c|c|c|c|c|c|}
\hline $\begin{array}{c}\text { Pd } \\
\text { contents } \\
\left(\mathrm{mg} \cdot \mathrm{g}^{-1}\right)\end{array}$ & 0 & $10^{-3}$ & $10^{-2}$ & $10^{-1}$ & 1 & 10 \\
\hline 0 & & $\Theta$ & $\theta$ & $\Theta 6$ & $\Theta$ & $\theta$ \\
\hline $10^{-3}$ & ns & & ns & ns & $\mathrm{ns}$ & ns \\
\hline $10^{-2}$ & ns & ns & & ns & ns & ns \\
\hline $10^{-1}$ & $6 U$ & $6 U$ & $6 U$ & & $\mathrm{~ns}$ & ns \\
\hline 1 & $6 U$ & $U$ & $U$ & $\mathrm{~ns}$ & & ns \\
\hline 10 & ns & Ş & Ş & ns & $\mathrm{ns}$ & \\
\hline
\end{tabular}

Lolium perenne

At the end of the exposure time, for Festuca arundinacea, Organic content/fresh matter (6) differs significantly between the Control and plants exposed to $10^{-1} \mathrm{mg} / \mathrm{g} \mathrm{Pd}$.

The stretched length $(\Theta)$ is significantly different among the various soil contents. This significant difference is observed during the exposure time from D10 to D60. By focusing on this trait, one observes that at the beginning of the test (D9 to D 16), the average stretched length of all plants is similar $(\sim \pm 1 \mathrm{~cm})$. After D10, $\Theta$ values for plants exposed to $10 \mathrm{mg}^{-\mathrm{g}^{-1}} \mathrm{Pd}$ become higher than the others (i.e. $+2 \mathrm{~cm}$ compared to the uncontaminated Control). After D24, until the end of tests, this difference is all the more marked. On average, for plants exposed to $10^{-3}, 10^{-2}, 10^{-1}, 1$ and $10 \mathrm{mg}^{-1} \mathrm{~g}^{-1} \mathrm{Pd}$, there are respectively about 7,9 , 5,8 and $7 \mathrm{~cm}$ less than plants Control. The difference in the $\Theta$ values between the Pd-exposed and the uncontaminated plants is apparent even at the lowest Pd-addition. It thus seems to be a threshold effect for Pd that occurs close to insitu content values, i.e. $<10^{-3} \mathrm{mg} \cdot \mathrm{g}^{-1} \mathrm{Pd}$. This indicates that the stretched length, which is readily measurable in-situ, should be further evaluated on indigenous Festuca arundinacea used as a passive bio-indicator in order to possibly monitor the Pd intake into food chains. 
For Lolium perenne, 3 traits (Ş: SLA; 6: Organic content / fresh matter; $U$ : Water content) exhibit significant difference with increasing $\mathrm{Pd}$ contaminations. The trait 6 differs significantly between the plants exposed to $10^{-1} \mathrm{mg} \cdot \mathrm{g}^{-1}$ and lower level contamination tests (i.e. Control, $10^{-3}$ and $10^{-2} \mathrm{mg} . \mathrm{g}$ $\left.{ }^{1}\right)$. This corresponds to an average $3 \%$ loss of organic content. A significant difference was also observed between the uncontaminated Control and plants from $1 \mathrm{mg} \cdot \mathrm{g}^{-1} \mathrm{Pd}$ soils ( $6 \%$ organic content loss).

Concerning Water content $(U)$, some significant differences appear between $10^{-1} \mathrm{mg} \cdot \mathrm{g}^{-1}$ and lower contaminations levels ( $\sim 3 \%$ water content loss). This was equally observed for plants from $1 \mathrm{mg}^{-1} \mathrm{~g}^{-1} \mathrm{Pd}$ soils (11\% water content loss). One possible explanation would be the hydric stress caused by the high contamination exposure $\left(1 \mathrm{mg} . \mathrm{g}^{-1}\right)$ on this specie.

Finally, for SLA (Ş), two significant differences were observed between the highest contamination level $\left(10 \mathrm{mg} \cdot \mathrm{g}^{-1} \mathrm{Pd}\right)$ and $10^{-3} \mathrm{mg} \cdot \mathrm{g}^{-1}$ or $10^{-2} \mathrm{mg}^{-g^{-1}}$ $\mathrm{Pd}$. The mean difference in SLA between the relating plants is $\sim 14 \mathrm{~mm}^{2} . \mathrm{mg}^{-1}$. This underlines the potential effect of the extreme Pd-content exposures on plants' photosynthetic surface decrease.

\section{$\underline{\text { PAH Phytotoxicity Tests }}$}

\section{Germination Tests}

As concerns Trifolium repens, high $\Sigma_{13} \mathrm{PAH}$ exposure inhibits the germination of seeds. Compared to the Control, delayed (4 days) germination was observed for seeds exposed to $10^{-1} \mathrm{mg} \cdot \mathrm{g}^{-1} \Sigma_{13} \mathrm{PAH}$.

\section{Functional Traits Responses}

Changes in the functional traits for Trifolium repens and Lotus corniculatus are presented in Figure 6. This regards [Stretched length] $(\Theta)$; [Specific leaf area] (Ş); [Organic content / fresh matter] (6); [Organic content / dry matter] (П); [Minerals content/ fresh matter] $(\Phi)$; [Minerals content / dry matter] $(\Psi)$; [Fresh mass] $(£)$; [Water content] $(\Theta)$; [Leaves number] $(X)$. Some traits are linked (e.i. $\Phi$ and $\Psi$ ). They allow achieving a certain assessment of results consistency.

For Trifolium repens a threshold effect is obviously reached at $10^{-1} \mathrm{mg} \cdot \mathrm{g}^{-1}$ $\Sigma_{13}$ PAH. Several functional traits have notably been affected by this contamination level and the plants rapidly died as apparent by sight in by 5 traits: (Minerals content/ fresh matter $(\Phi)$; Minerals content / dry matter $(\Psi)$; Fresh mass $(£)$; Water content $(\Theta)$; Stretched length $(\Theta)$ and Leaves number $(\searrow)$. Among them, two are of practical interest: fresh matter and the leaves number. Significant changes in the leaves number occur at D47 (with an average difference of 7 leaves between the Control and plants exposed to the highest contamination level, i.e. $10^{-1} \mathrm{mg}^{-\mathrm{g}^{-1}}$ ). The difference accentuates over time and reaches 94 leaves (out of 120) at the end of the test. 
As for Lotus corniculatus, several functional traits have been affected by $\Sigma_{13}$ PAH contamination at $10^{-2}$ and $10^{-1} \mathrm{mg}^{-1} \mathrm{~g}^{-1}$ : water content $(U)$, stretched length $(\Theta)$, leaves number $(X)$, organic content $(6)$ and fresh matter $(£)$. Compared to $T$. repens, fewer traits respond significantly. It is worth noting that, throughout all the test duration, L.corniculatus plants exposed to $10^{-2}$ mg. ${ }^{-1} \Sigma_{13}$ PAH displayed a pronounced development, which resulted in significantly positive effects on the tested biological traits. For instance, at D60, a difference of 80 leaves (out of 160) is observed between the Control and plants exposed at $10^{-2} \mathrm{mg}^{-1} \mathrm{~g}_{13} \mathrm{PAH}$, whereas for the same duration, the difference between Control and the extreme content $\left(10^{-1} \mathrm{mg} \cdot \mathrm{g}^{-1} \Sigma_{13} \mathrm{PAH}\right)$ is 63 leaves.

Figure 6. Changes in Functional Traits for Trifolium repens (Right-hand Side) and Lotus corniculatus (Left-hand Side): Average-to-average Comparisons (ns: No Significant Difference) $\left({ }^{a}:\right.$ High Values Measured on Plants Exposed to $\left.10^{-2} \mathrm{mg}^{-1} \mathrm{~g}_{13} \mathrm{PAH}\right)$

\begin{tabular}{|c|c|c|c|c|c|c|c|}
\hline $\begin{array}{c}\sum_{13} \text { PAHs } \\
\text { contents } \\
\left(\mathrm{mg.g}^{-1}\right)\end{array}$ & $\mathbf{0}$ & $10^{-6}$ & $10^{-5}$ & $10^{-4}$ & $10^{-3}$ & $10^{-2}$ & $10^{-1}$ \\
\hline $\mathbf{0}$ & & ns & ns & ns & ns & $\mathrm{ns}$ & ПФЧ£Х \\
\hline $10^{-6}$ & 6 & & $\mathrm{~ns}$ & $\mathrm{~ns}$ & $\mathrm{~ns}$ & $\mathrm{~ns}$ & ПФЧ£Х \\
\hline $10^{-5}$ & $6 \Theta$ & ns & & ns & ns & ns & ПФЧ£Х \\
\hline $10^{-4}$ & $\mathrm{~ns}$ & $\mathrm{~ns}$ & $\mathrm{~ns}$ & & $\mathrm{~ns}$ & $\mathrm{~ns}$ & 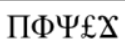 \\
\hline $10^{-3}$ & $\theta$ & ns & $\mathrm{ns}$ & ns & & ns & 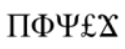 \\
\hline $10^{-2}$ & $£^{a} U X^{a}$ & $6 £^{a} U X^{a}$ & ${ }^{b} £^{a} U X^{a}$ & $6 £^{a} U X^{a}$ & $6 £^{a} U X^{a}$ & & ПФЧ£Х \\
\hline $10^{-1}$ & 6UOX & 6UӨx & 6UOx & 6UAx & 6UӨx & $£ \Theta x$ & \\
\hline
\end{tabular}

\section{Lotus corniculatus}

As a consequence, compared to Lotus corniculatus, Trifolium repens seems to be more sensitive to $\Sigma_{13} \mathrm{PAH}$ exposure. Because of its higher number of traits which significantly respond (in particular leaves number), it must be further studied in order to assess its potential as in-situ bio-indicator.

\section{Conclusions}

Through TC and AI, this study shows that vehicular Pd and PAH fallout is mostly found within the first 20 meters from the carriageway. Regarding Pd no effect of the hedge tree is noticed while for $\Sigma_{13} \mathrm{PAH}$ a "tree hedge effect" is observed by the increasing contaminations levels near such a natural barrier. 
Among the analyzed organisms, earthworms and plant communities were the most accumulative.

From these observations and based on the scarce literature studies, 4 species usually shown in highway ROW were selected for phytotoxicity tests in the aim to reveal possible candidates for passive bio-monitoring. The tests reveal that for Palladium, Festuca arundinacea through its stretched length, and for PAH, Trifolium repens through its leaves number, could be in-situ bioindicators. The effects of the tested pollutants on the measured traits usually occur after 30 days. Besides, because phytotoxicity tests' conditions are far from the real (on site) ones, several limits ought to be set for current results. For instance, one major limitation lies in the Pd-PAHs and/or organisms' interactions with other vehicular pollutants. This point must be further examined. As a consequence, a second phytotoxicity experiment involving roadside soils is scheduled with $3 \mathrm{Pd}$ and PAHs exposure contents, corresponding to Control (0), in-situ common and extremes contents, respectively with Trifolium pratense and Festuca arundinacea. The same traits will be measured + a physiologically one (omega- 3 index). These first results will allow concluding about the influence of the natural soil and the role of others pollutants on species responses.

\section{Acknowledgments}

Our thanks to Mr. M. Galet and Mr. G. Cosson (Cofiroute) for their assistance in the carrying-out of this study (access to ROW and safety), as well as the Pessac (Inra) and Leesu (Univ. Paris Est) staffs for their help with sampling and analyzes. Thanks to T. Lorino (IFSTTAR) for his help in statistical analyzes. This work was financially supported by the French environmental agency (Ademe) and Ifsttar.

\section{References}

Alam Cheema, S., Imran Khan, M., Tang, X., Zhang, C., Shen, C., Malik, Z., Shafaqat, A., Jianjun, Y., Kaili, S., Xincai, C., and Yingxu, C. Enhancement of phenanthrene and pyrene degradation in rhizosphere of tall fescue (Festuca arundinacea). Journal of Hazardous Materials. 166, 2-3 (July 2009) 12261231.ISSN0304-3894. DOI=http://doi:10.1016/j.jhazmat.2008.12.027.

Arienzo, M., Adamo, P., and Cozzolino, V. The potential of Lolium perenne for revegetation of contaminated soil from a metallurgical site. Science of The Total Environment. $319, \quad 1-3 \quad$ (2004) $\quad 13-25$. DOI= http://doi:10.1016/S00489697(03)00435-2.

AFNOR, 2005. Toxicité chronique sur les plantes supérieures [Chronic toxicity in higher plants]. NF ISO 22030, 33(0).

Benedict, W. G. Some morphological and physiological effects of palladium on Kentucky bluegrass. Canadian Journal of Botany. 48, 1 (1970) 91-93. DOI = http://doi: 10.1139/b70-012. 
Brenchley, W. E. The effect of rubidium sulphate and palladium chloride on the growth of plants. Ann App Biol. 21 (1934) 398-417. DOI = http://doi: 10.1111/j.1744-7348.1934.tb06686.x.

Chi hua, H., and Banks, M. K. Degradation of Polycyclic Aromatic Hydrocarbons in the Rhizosphere of Festuca arundinacea and Associated Microbial Community Changes. Bioremediation Journal. 10, 3 (2006) 93-104. DOI $=$ http://doi. 10.1080/10889860600939609.

Clement, N., Muresan, B., Hedde, M., François, D. PAH dynamics in roadside environments: Influence on the consistency of diagnostic ratio values and ecosystem contamination assessments, Science of the Total Environment. 538 (2015) 997-1009.

Cornelissen, J. H. C., Lavorel, S., Garnier, E., Díaz, S., Buchmann, N., Gurvich, D. E., Reich, P. B., Steege, H. ter, Morgan, H. D., Heijden, M. G. A., van der Pausas. J. G., and Poorter, H. A handbook of protocols for standardised and easy measurement of plant functional traits worldwide. Australian Journal of Botany. 51(2003) 335-380. DOI= http://dx.doi.org/10.1071/BT02124.

Ek, K. H., Rauch, S., Morrison, G. M., Lindberg, P. Platinum group elements in raptor eggs, faeces, blood, liver and kidney. Science of The Total Environment. 334335(2004) 149-159.

Fletcher, J. Keynote speech: a brief overview of plant toxicity testing. In: Gorsuch, JW., Lower, W-R., Wang, W., Lewis, M-A. (Eds.). Plants for Toxicity Assessment. Eds. American Society for Testing and Materials STP 1115, Philadelphia. (1991) 5-11.

Gateuille, D., Evrard, O., Lefevre, I., Moreau-Guigon, E., Alliot, F., Chevreuil, M., and Mouchel, J-M. Combining measurements and modelling to quantify the contribution of atmospheric fallout, local industry and road traffic to PAH stocks in contrasting catchments. Environmental Pollution. 189 (2014) 152-160. DOI = doi: http://10.1016/j.envpol.2014.02.029.

Giordano, S., Adamo, P., Spagnuolo, V., and Vagliec, B-M. Instrumental and biomonitoring of heavy metal and nanoparticle emissions from diesel engine exhaust in controlled environment. Journal of Environmental Sciences. 22, 9 (September 2010) 1357-1363. DOI = http://doi:10.1016/S1001-0742(09)60262-X.

Gomez, B., Palacios, A., Gomez, M., Sanchez, J-L., Morrison, G., Rauch, S., McLeod, C., Ma, R., Caroli, S., Alimonti, A., Petrucci, F., Bocca, B., Schramel, P., Zischka, M., Petterson, C., and Wass, U. Levels. Risk assessment for humans and ecosystems of platinum-group elements in airborne particles and road dust of some European cities. Science of the Total Environment. 299 (2002) 1-19.

Gonzalez, Y., and Rodriguez, S. A comparative study on the ultrafine particle episodes induced by vehicle exhaust: A crude oil refinery and ship emissions. Atmospheric Research.120-121 (2013) 43-54. DOI = http://doi:10.1016/j.atmosres.2012.08.001.

Gross, N. Mécanismes de structuration des prairies subalpines: apport des traits fonctionnels [Mechanisms for structuring subalpine meadows: contribution of functional traits]. Thesis. 2007.

Helmers, E., and Kummerer, K. Sources and sinks of anthropogenic platinum fluxes. In: Zereini, F., Alt, F., editors. Anthropogenic platinum-group element emissions, their impact on man and environment. Berlin, Heidelberg: Springer-Verlag. (2000) 15-24.

Henner,P., Schiavon, M., Druelle, V., and Lichtfouse, E. Phytotoxicity of ancient gaswork soils. Effect of polycyclic aromatic hydrocarbons (PAHs) on plant 
germination. Catena. 129 (1999) 30-38. DOI $=$ doi:10.1016/S01466380(99)00080-7.

Huang, X. D., El-Alawi, Y., Penrose, D. M., Glick, B. R., and Greenberg, B. M. A multi-process phytoremediation system for removal of polycyclic aromatic hydrocarbons from contaminated soils. Environmental pollution. 130, 3 (August 2004) 465-476.

ISO/DIS 17294-1: Water Quality-Application of inductively coupled plasma mass spectrometry (ICP-MS) for the determination of elements-Part 1: General guidelines and basic principles. (2003).

ISO/DIS 17294-2: Water Quality-Application of inductively coupled plasma mass spectrometry (ICP-MS) for the determination of elements-Part 2: Determination of 61 elements. (2002).

Jones K. C., and de Voogt, P. Persistant organic pollutants: state of science. Environmental Pollution. 100, (1999) 209-221.

Jullien, A., and François, D. Soil indicators used in road environmental impact assessment. Resources Conservation and Recycling. 48 (2006) 101-124.

MacKay, D., and Shin, W. Y. 1991. Illustrated handbook of physical-chemical proporties and environmental fate of organics chemicals, II, Lewis, Chelsea, Mich Publishers.

OCDE. Ligne directrice de l'OCDE pour les essais de produits chimiques [OECD Guidelines for the Testing of Chemicals]. (2006) 27.

Schäfer, J., Hannker, D., Eckhardt, J. D., and Stüben, D. Uptake of traffic-related heavy metals and platinum group elements (PGE) by plants. Science of the Total Environment. 215 (1998) 59-67.

Smith, M. J., Flowers, T-C., Duncan, H-J., and Alder, J. Effects of polycyclic aromatic hydrocarbons on germination and subsequent growth of grasses and legumes in freshly contaminated soil and soil with aged PAHs residues. Environmental pollution. 141, 3 (2006) 519-525. DOI = http://doi:10.1016/j.envpol.2005.08.061.

Smith, M. J., Flowers, T-C., Duncan, H-J., and Saito, H. Study of PAH dissipation and phytoremediation in soils: comparing freshly spiked with weathered soil from a former coking works. Journal of hazardous materials. 192, 3 (2011) 1219-1225. DOI = http://doi:10.1016/j.jhazmat.2011.06.033.

US-EPA. 2008. Polycyclic Aromatic Hydrocarbons (PAHs). Office of Solid Waste. United States Environmental Protection Agency. 3pp. PDF version freely accessible at http://1.usa.gov/1FSFc3Y.

Vernay, P., Austruy, A., Gauthier-Moussard, C., and Hitmi, A. Germination et fonctionnement du système photosynthétique des végétaux comme bioindicateurs de pollution des sols [Germination and functioning of the photosynthetic system of plants as bio-indicators of soil pollution]. Study and Soil Management. Etude et Gestion des Sols. 16, 3/4 (2009) 349-357.

Viskari, E-L., Rekilä, R., Roy, S., Lehto, O., Ruuskanen J., and Kärenlampi, L. Airborne pollutants along a roadside: Assessment using snow analyses and moss bags. Environmental Pollution 97, 1-2 (1997) 153-160. DOI = http://doi:10.1016/S0269-7491(97)00061-4.

Wang,J., Guijian, L., Lanlan, L., Jiamei, Z., and Houqi, L. Geochemical normalization and assessment of heavy metals $(\mathrm{Cu}, \mathrm{Pb}, \mathrm{Zn}$, and $\mathrm{Ni})$ in sediments from the Huaihe River, Anhui, China. Catena. 129 (June 2015) 30-38. DOI = http://doi:10.1016/j.catena.2015.02.008.

Zereini, F., and Alt, F. Palladium emissions in the environment: Analytical Methods, Environmental Assessment and Health Effects. Springer ed. ISBN: 978-3-54029219-7. 2006. 
Zereini, F., Wiseman, C., and Puettmann, W. Changes in palladium, platinum and rhodium concentrations, and their spatial distribution in soils along a major highway in Germany from 1994 to 2004. Environmental Science and Technology. (2007) 451-456. DOI = http://doi: 10.1021/es061453s. 